\title{
EDITORIAL
}

\section{Turning up the heat on fever research?}

Intensive care unit (ICU) clinicians expend considerable effort measuring and manipulating body temperature in critically ill patients. A great deal of anxiety is expended worrying about both fever and hypothermia, and yet, the evidence to support clinical decisions about temperature management is limited. In this issue of Critical Care and Resuscitation, investigators have gone back to the basics with three studies that turn up the heat on fever research. ${ }^{1-3}$

Cutuli and colleagues ${ }^{1}$ conducted a systematic review and meta-analysis evaluating the accuracy of non-invasive body temperature measurement methods in adult patients admitted to the ICU. They identified studies that compared the accuracy and precision of non-invasive peripheral thermometers in ICU patients with intravascular temperature measures. They also compared a range of invasive extravascular methods for monitoring temperature (eg, oesophageal monitoring) with intravascular temperature measures. Although the available data are limited, the findings still have important clinical implications. The bottom line is that none of the devices tested provided either accurate or precise measurements of core body temperature. Contrary to conventional wisdom, non-invasive peripheral thermometers do not consistently provide lower readings than intravascular monitoring. For example, the core temperature measured by a pulmonary artery catheter can easily be more than $1^{\circ} \mathrm{C}$ higher or lower than a contemporaneously measured tympanic temperature. Decisions to investigate and/or initiate treatment for individual patients are often based on whether the documented body temperature is above a particular threshold value $\left(e g, 38^{\circ} \mathrm{C}\right)$. Accordingly, the finding that devices for monitoring body temperature lack precision is important for clinicians and should lead them to reconsider the approach of basing decisions on threshold values. Irrespective of the method used to monitor temperature, the best approach for clinicians is probably to reframe how one interprets the documented body temperature. Instead of focusing on the discrete value, clinicians should instead consider the range of true body temperatures that the documented value might represent. While Cutuli and colleagues $^{1}$ suggest that oesophageal temperature monitoring might be preferred to other methods, even this method of monitoring has a pooled $95 \%$ limit of agreement of -0.39 to 0.51 , highlighting the importance of considering more than the discrete value documented, even when oesophageal monitoring is used.

When one decides that the patient's body temperature is too high, a range of physical cooling devices are available to achieve normothermia. As occurs commonly in medicine, new device technology has entered clinical practice in advance of a strong supporting evidence base. The article by Anstey and colleagues ${ }^{2}$ suggests that in febrile patients with septic shock, the Artic Sun 5000 (BARD) external water-based temperature control device allows precise temperature control and is associated with low occurrence of body temperatures over $38^{\circ} \mathrm{C}$. This is useful information; however, while this report describes precise temperature control targeting an oesophageal temperature of $37^{\circ} \mathrm{C}$, it does not identify that this is the optimal target. The optimal target can only be established through randomised controlled trials. The data presented in this study hint at potential difficulties that may be encountered in attempting to do this. Data on energy transfer suggest that although considerable energy was required to achieve and maintain normothermia on the first day of temperature control, this requirement was very short-lived. Presumably, this reflects a low underlying burden of fever beyond the first day in patients with sepsis. If this is the case, it may prove difficult to achieve temperature separation between treatment groups in a randomised controlled trial after the first day of treatment. This finding accords with observations in previous randomised controlled trials evaluating fever control methods in patients with sepsis, where fever abated rapidly in most patients. ${ }^{4-6}$

Following the theme of investigating device technologies that are used in practice without strong supporting evidence, Yanase and colleagues ${ }^{3}$ used a before-and-after design to evaluate the haemodynamic effects of room versus body temperature $100 \mathrm{~mL}$ boluses of $20 \%$ albumin in patients after cardiac surgery. Fluid warmers are devices that are widely used, despite limited evidence that they improve outcomes. The investigators reported that administering 


\section{EDITORIAL}

warmed fluids was not associated with the reductions in body temperature that were seen in association with the use of room temperature fluids. However, such temperature reductions were trivial in any case and, based on the limited differences in haemodynamic variables for room temperature versus body temperature fluids, unlikely to be clinically consequential.

These three studies are useful additions to the literature but further simple studies that evaluate monitoring of body temperature and temperature manipulation are needed to advance evidence-based temperature management in the critically ill.

\section{Competing interests}

None declared.

\section{Author details \\ Paul J Young ${ }^{1,2}$ \\ 1 Medical Research Institute of New Zealand, Wellington, New Zealand \\ 2 Intensive Care Unit, Wellington Hospital, Wellington, New Zealand}

Correspondence: paul.young@ccdhb.org.nz

\section{References}

1 Cutuli SL, See EJ, Osawa EA, et al. Accuracy of non-invasive body temperature measurement methods in adult patients admitted to the intensive care unit: a systematic review and meta-analysis. Crit Care Resusc 2021; 23: 6-13.

2 Anstey JR, Forrest PR, Cass $\mathrm{H}$, et al. Sustained normothermia in septic shock and the energy transfer required: a report of a pilot feasibility study using newer-generation surface cooling devices. Crit Care Resusc 2021; 23:113-16.

3 Yanase F, Cutuli SL, Naorungroj T, et al. Temperature and haemodynamic effects of a $100 \mathrm{~mL}$ bolus of $20 \%$ albumin at room versus body temperature in cardiac surgery patients. Crit Care Resusc 2021; 23: 14-23.

4 Young PJ, Bellomo R, Bernard GR, et al. Fever control in critically ill adults. An individual patient data meta-analysis of randomised controlled trials. Intensive Care Med 2019; 45: 468-76.

5 Young P, Saxena M, Bellomo R, et al. Acetaminophen for fever in critically ill patients with suspected infection. N Engl J Med 2015; 373: 2215-24

6 Young PJ, Bailey MJ, Bass F, et al. Randomised evaluation of active control of temperature versus ordinary temperature management (REACTOR) trial. Intensive Care Med 2019; 45: 1382-91. 